\title{
PENDATAAN KOPERASI PADA DINAS KOPERASI DAN UKM KOTA TERNATE BERBASIS WEB
}

\author{
Rosihan $^{1}$, Salkin Lutfi ${ }^{2}$ \\ Program Studi Teknik Informatika, Fakultas Teknik, Universitas Khairun \\ Jl.Jati Metro, Kota Ternate Selatan \\ E-mail : Rosihan.unkhair@outlook.com ${ }^{1}$,Salkin.lutfi@gmail.com²
}

\begin{abstract}
The need for Information and Communication Technology (ICT) is very important in improving the performance of an agency, as in the Office of Cooperatives and SMEs Ternate City. Cooperative data processing is still done manually resulting in data can be lost or damaged. Another disadvantage is that it takes much longer time in both storing and retrieving cooperative data, not to mention requiring a larger space. Data access is also very limited because it can only be done from the office only. By utilizing a webbased information system concept the above problems can be resolved. Cooperative data so much safer, faster in storing and accessing back and require a small media that is the hard drive compared to the closet. Utilization of web programming makes the cooperative data collection system can be accessed anywhere and anytime.
\end{abstract}

Keywords: Cooperative Data Collection, Web

Abstrak -- Kebutuhan akan Teknologi Informasi dan Komunikasi (TIK) sangat penting dalam meningkatkan kinerja dari sebuah instansi, seperti halnya di Dinas Koperasi dan UKM Kota Ternate. Pengolahan data koperasi yang masih dilakukan secara manual mengakibatkan data bisa hilang atau rusak. Kerugian lain adalah membutuhkan waktu yang lebih lama baik dalam menyimpan dan mencari kembali data koperasi, belum lagi membutuhkan ruang yang lebih besar. Pengaksesan data juga sangat terbatas karena hanya bisa dilakukan dari kantor saja. Dengan memanfaatkan sebuah konsep sistem informasi berbasis web permasalahan di atas dapat teratasi. Data koperasi jadi lebih aman, cepat dalam menyimpan dan mengakses kembali serta membutuhkan media yang kecil saja yakni harddisk dibandingkan dengan lemari. Pemanfaatan pemrograman web membuat sistem pendataan koperasi dapat diakses di mana dan kapan saja.

Kata Kunci: Pendataan Koperasi, Web

\section{PENDAHULUAN}

Dalam Era globalisasi saat ini, teknologi informasi mempunyai peranan penting dalam kehidupan manusia. Perkembangan dalam bidang komputer baik perangkat keras maupun aplikasi di dalamnya telah memberikan kemudahan bagi manusia dalam menyelasaikan pekerjaan sehingga dapat lebih efektif dan efisien. Tak heran banyak teknologi komputer telah mengambil peran penting dalam kehidupan manusia termasuk pada sebuah institusi baik pemerintah maupun swasta.

Dalam suatu instansi pemerintah, keinginan untuk maju selalu ada. Hampir dipastikan sudah menjadi salah satu target jangka panjang yang telah direncanakan sejak berdirinya instansi pemerintah tersebut. Kecepatan penyampaian informasi dan akses data kepada masyarakat merupakan salah satu indikator sebuah keberhasilan instansi pemerintah dalam menjalankan tugasnya sebagai mitra masyarakat.

Dinas Koperasi Kota Ternate sebagai salah satu instansi yang termasuk dalam kategori di atas, senantiasa menginginkan suatu kemajuan. Keadaan ini belum terlaksana, hal ini dapat dilihat dalam pendataan Koperasi masih menggunakan cara manual. Penyimpanan data masih dilakukan satu per satu dalam lemari penyimpanan sehingga pencarian data tidak efisien dalam hal waktu dan tenaga.

Melihat keadaan ini Dinas Koperasi dan UKM Kota Ternate membutuhkan perubahan penanganan data koperasi. Diperlukan suatu sistem yang memberi kemudahan kepada pihak Dinas Koperasi dan UKM Kota Ternate untuk publikasikan informasi Koperasi secara luas serta penyimpanan data lebih aman. Oleh karena itu penulis tertarik melakukan penelitian dengan judul "Sistem Informasi Pendataan Koperasi pada Dinas Koperasi dan UKM Kota Ternate Berbasis Web".

\section{KAJIAN PUSTAKA}

\subsection{Konsep Dasar Sistem}

Sistem yang dimaksudkan di sini, bukanlah merupakan sistem yang hanya terdiri atas satu modul tunggal saja. Sistem umumnya tersusun atas sejumlah sistem-sistem atau modul-modul yang lebih kecil, yang kita kenal dengan sebutan subsistem. Subsistem-subsistem yang menyusun sebuah sistem, memiliki batasannya masing- 
masing, namun tetap saling berinteraksi untuk mencapai satu tujuan yang sama. Interaksi yang menghubungkan antar subsistem yang satu dengan subsistem yang lain disebut antarmuka subsistem (interface) atau penghubung system [1].

\subsection{Karakteristik Sistem}

Suatu sistem mempunyai karakteristik atau sifat-sifat tertentu, yaitu mempunyai komponenkomponen sistem, batasan sistem, lingkungan luar sistem, penghubung sistem, masukan sistem, keluaran sistem, dan pengelolaan sistem, sebegai uraian berikut [1] :

1. Komponen Sistem

2. Batasan Sistem

3. Lingkungan Luar Sistem

4. Penghubung Sistem

5. Masukan Sistem

6. Keluaran Sistem

7. Pengelolaan Sistem

\subsection{Konsep Dasar Informasi}

Informasi merupakan hal penting dan mempunyai pengaruh besar bagi suatu sistem. Data harus dibedakan dengan informasi, perbedaan itu sangat jelas dan sangat penting untuk maksud tertentu. Data adalah kenyataan yang menggambarkan suatu kejadian-kejadian atau peristiwa dan yang tidak berlaku dalam proses keputusan, dan selalu menerima bentuk laporanlaporan masa lampau yang dicatat dan disimpan secara tidak langsung di peroleh kembali untuk mengambil keputusan.

Karakteristik dan tipe-tipe informasi akan terkait dengan kebutuhan informasi pada tingkatan-tingkatan manajemen dalam organisasi. Sistem informasi berfungsi mentransformasikan data menjadi informasi yang bernilai bagi tiap tingkatan manajemen. Sistem informasi mendukung pembuatan keputusan sesuai tahaptahap pembuatan keputusan manajemen dalam organisasi.

Menurut Mcleod "Sistem Informasi merupakan sistem yang mempunyai kemampuan untuk mengumpulkan informasi dari semua sumber dan menggunakan berbagai media untuk menampilkaninformasi [1].

\subsection{Pegertian Pendataan}

Pendataan data adalah proses memasukkan data ke dalam media sistem pendataan data. Jika media sistem Pendataan data tersebut berupa buku, Pendataan data dilakukan dengan menulis pada lembar lembar buku. Jika sistem Pendataan data berupa perangkat komputer, Pendataan dilakukan dengan mengetik melalui keyboard, penggunaan pointer mouse, alat scanner (pembaca gambar), atau kamera video. Yang termasuk dalam Pendataan data adalah aktivitas penulisan ke buku atau kertas, pemasukan data ke dalam komputer [2].

\subsection{Pengertian Koperasi Umum}

Koperasi adalah badan hukum yang berdasarkan atas asas kekeluargaan yang anggotanya terdiri dari perorangan atau badan hukum dengan tujuan untuk mensejahterakan anggotanya. Berikut ini ada tiga fungsi macam koperasi :

1. Konsumsi koperasi adalah menyediakan keperluan sehari-hari bagi anggotanya.

2. Produksi koperasi adalah koperasi yang membuat barang dan dijual bersama-sama.

3. Simpan pinjam koperasi adalah koperasi yang khusus bertujuan melayani atau mewajibkan anggotanya untuk menambah disamping dapat memberikan pinjaman kepada anggotanya.

\subsection{Dinas Koperasi dan UKM Kota Ternate}

Dinas Koperasi dan UKM Kota Ternate terbentuk berdasarkan Peraturan Daerah Kota Ternate nomor 15 tahun 2007 tentang organisasi dinas-dinas daerah Kota Ternate yang berkedudukan sebagai unsur pelaksana pemerintah daerah yang dipimpin oleh seorang kepala dinas yang berada di bawah dan bertanggug jawab kepada kepala daerah melalui sekretaris daerah.

Menurut Kabid Tata Usaha Dinas Koperasi dan UKM Kota Ternate, koperasi yang berada di Kota Ternate kurang lebih ada sekitar 200 koperasi baik yang aktif dan tidak aktif.

Ada tiga macam fungsi koperasi yang ada di Kota Ternate :

1. Konsumsi koperasi yang berfungsi untuk menyediakan keperluan sehari-hari anggotanya.

2. Produksi koperasi adalah koperasi yang membuat barang dan di jual bersama -sama.

3. Simpan pinjam koperasi adalah koperasi yang khusus bertujuan melayani atau mewajibkan anggotanya untuk menambah di samping dapat memberikan pinjaman kepada anggotanya.

\subsection{WWW (Word wide web)}

Www atau world wide web atau web saja merupakan sebuah sistem yang saling terkait dalam sebuah dokumen yang berformat hypertext yang berisi beragam informasi, baik tulisan, gambar, suara, video, dan informasi multimedia lainnya dan dapat diakses melalui sebuah perangkat yang disebut web browser. Untuk menterjemahkan dokumen dalam bentuk hypertext ke dalam bentuk dokumen yang bisa dipahami, maka web browser melalui web client akan membaca halaman web yang tersimpan di sebuah web server melalui protocol yang biasa disebut http atau Hypertext Transfer Protocol [2]. 


\subsection{Metode Pengembangan Perangkat Lunak Waterfall}

Metode pengembangan perangkat lunak yang digunakan dalam penelitian ini adalah model waterfall. Model waterfall adalah suatu model proses untuk memodelkan suatu system perangkat lunak yang dibuat secara terstruktur dan berurutan dimulai dari penentuan analisa kebutuhan, desain sistem, penulisan kode program, pengujian program, dan penerapan program. Bagan dari model waterfall dapat dilihat pada Gambar 1.

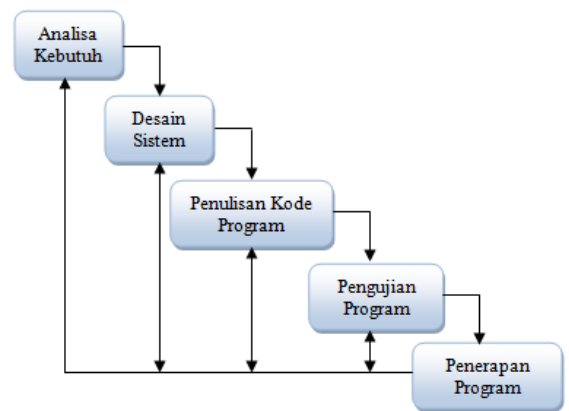

Gambar 1. Model Waterfall

\subsection{DFD (Data Flow Diagram)}

Data Flow Diagram (DFD) merupakan alat untuk membuat diagram yang serbaguna. Data flow diagram terdiri dari notasi penyimpanan data (data store), proses (prosess), aliran data (flow data), dan sumber masukan (entity). untuk lebih jelasnya dapat dilihat simbol DFD pada Tabel 1.

Tabel 1. Simbol DFD (Yakub. 2012)

\begin{tabular}{|c|c|c|}
\hline No & Simbol & Fungsi \\
\hline 1 & & $\begin{array}{l}\text { External Entity (kesatuan luar), untuk menggambarkan sumber } \\
\text { asli suatu transaksi, serta penerimaan akhir dari sistem }\end{array}$ \\
\hline 2 & & $\begin{array}{l}\text { Data Flow(arus data), untuk menggambarkan arus data yang } \\
\text { mengalir sebagai input atau output }\end{array}$ \\
\hline 3 & Data store & Menyimpan data atau tempat data direfer dan proses \\
\hline 4 & & $\begin{array}{l}\text { Orang, unit yang mempergunakan atau melakukan } \\
\text { transformasi data . } \\
\text { Komponen fisik tidak diidentifikasi }\end{array}$ \\
\hline
\end{tabular}

\subsection{Basis Data}

Basis Data adalah sekelompok item-item data yang saling terkait satu dengan yang lainnya yang di organisasikan berdasarkan skema atau struktur tertentu, tersimpan dalam sebuah storage/tempat dan dengan bantuan software dapat dilakukan manipulasi sesuai dengan kebutuhan. Basis Data adalah kumpulan dari tabel-tabel yang saling berelasi, disusun secara logis, sehingga bisa menghasilkan informasi yang bernilai dalam proses pengambilan keputusan [3].

Metode Entity Relationship yang berisi komponen-komponen himpunan entitas dan himpunan relasi yang masing-masing dilengkapi dengan atribut-atribut yang merepresentasikan seluruh fakta, dapat digambarkan dengan lebih sistematis menggunakan ERD. Tabel 2. memperlihat simbol-simbol yang digunakan dalam pembuatan ERD.

Tabel 2. Komponen Diagram E-R

\begin{tabular}{|c|c|c|}
\hline No & Simbol & Keterangan \\
\hline 1. & & $\begin{array}{l}\text { Entitas (entity) berfungsi untuk memberikan } \\
\text { identitas pada entitas yang memiliki label dan } \\
\text { nama }\end{array}$ \\
\hline 2. & & $\begin{array}{l}\text { Atribut berfungsi untuk memperjelas atribut } \\
\text { yang dimiliki oleh sebuah entitas }\end{array}$ \\
\hline
\end{tabular}




\begin{tabular}{|l|l|l|}
\hline 3. & & $\begin{array}{l}\text { Relasi berfungsi untuk mengetahui jenis } \\
\text { hubungan yang ada antara 2 file }\end{array}$ \\
\hline 4. & - & $\begin{array}{l}\text { Alur berfungsi untuk menghubungkan atribut } \\
\text { dengan entitas dan entitas dengan relasi }\end{array}$ \\
\hline
\end{tabular}

Pembuatan ERD dilakukan dalam dua tahap yaitu tahap pembuatan ERD awal (preliminary design) dan tahap optimasi ERD akhir (final design). Langkah-langkah teknik untuk menghasilkan ERD awal adalah :

1. Mengidentifikasikan semua himpunan entitas yang terlibat.

2. Atribut-atribut key dari masing-masing himpunan entitas.

3. Mengidentifikasikan dan menetapkan seluruh himpunan relasi diantara himpunan entitas himpunan entitas yang ada beserta foreign key-nya.

4. Menentukan derajat/kardinalitas relasi untuk setiap himpunan relasi.

5. Melengkapi himpunan entitas dan himpunan relasi dengan atribut-atribut deskriptif (non key). Pada tahap optimasi ERD akhir (final design) akan dilakukan koreksi terhadap hasil tahap pertama. Bentuk koreksi yang terjadi bisa berupa penggabungan himpunan entitas, pengubahan derajat relasi, penambahan relasi baru hingga pengubahan (penambahan dan pengurangan) atribut-atribut untuk tiap-tiap entitas.

\section{METEDOLOGI PENELITIAN}

\subsection{Langkah - Langkah Penelitian}

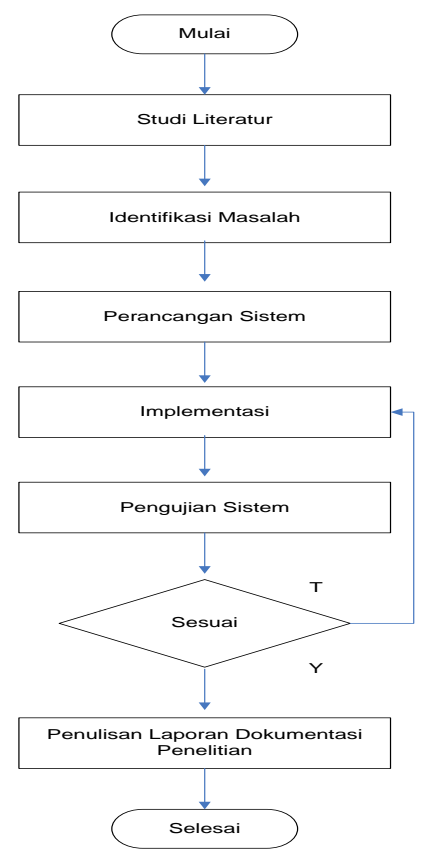

Gambar 2. Bagan alir penelitian sistem pendataan koperasi
Langkah-langkah yang dilakukan untuk pengembangan sistem dalam penelitian ini di bagi dalam langkah dengan urutan sebagai berikut (Gambar 2).

1. Studi literartur

Mencari bahan informasi dari bukubuku,refernsi dari jurnal serta datang langgsung ke tempat penelitian.

2. Ientifikasi Masalah

Penelitian ini dimulai dengan pendataan dan observasi pada penelitian serupa dan teoriteori yang mendukung. Kemudian dilanjutkan dengan pengumpulan data dan informasi sebagai bahan penelitian.

3. Analisis Masalah

Pada langkah ini dilakukan analisis untuk menentukan solusi apa yang dapat menyelesaikan masalah.

4. Perancangan Aplikasi

Pada langkah ini dilakukan pengumpulan data koperasi dan merancang aplikasi web.

5. Implementasi

Dengan menerapkan Perancangan Sistem Informasi Pendataan Koperasi pada Dinas Koperasi dan UKM Berbasis Web yang telah dirancang.

6. Pengujian Aplikasi

Pada langkah ini dilakukan pengujian Aplikasi Pendataan Koperasi pada Dinas Koperasi dan UKM Berbasis Web dengan simulasi pada versi online dilakukan dengan pengujian apilkasi serbagai fungsi perhitungan cepat rekap data yang di lakukan dengan menggunakan MySQL untuk data base dan Bahasa Pemrograman PHP.

\subsection{Diagram Konteks}

Koperasi pada Dinas Koperasi dan UKM Kota Ternate. Terdapat tiga entitas yaitu Operator, Kepala Seksi Bina Lembaga dan Kepala Dinas Koperasi. Entitas operator memberikan data kelompok koperasi, data Koperasi, data pendataan, data kecamatan dan data kelurahan, dari sistem akan memberikan laporan pendataan koperasi ke Kepala Seksi Bina Lembaga dan Kepala Dinas Koperasi. 


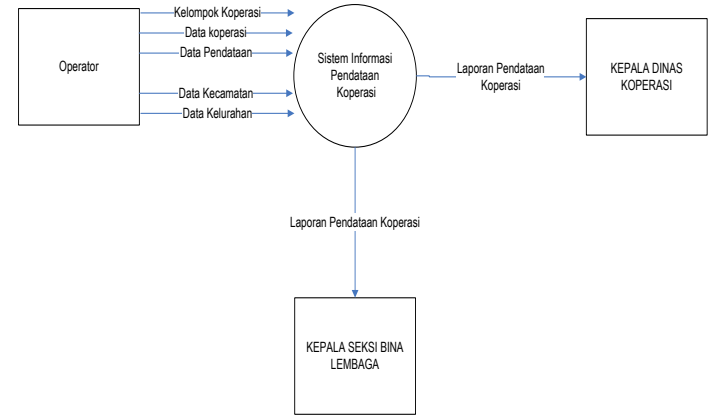

Gambar 3. Konteks Diagram Sistem Pendataan Koperasi

\subsection{Entity Relationship Diagram (ERD)}

Ada beberapa komponen utama pembetukan model entity relationship diagram yaitu entitas (entity) dan relasi (relation). Dalam entity relationship diagram hubungan relasi yang dapat terjadi antara himpunan entitas yang satu dengan entitas-entitas yang lain diantaranya seperti diagram yang digambarkan untuk hubungan antara entity dalam perancangan website Pada Dinas Koperasi dan UKM Kota Ternate.

Terdiri dari delapan tabel dengan entity tbl_admin, menu, tbl_kelompok_koperasi, tbl_koperasi, tbl_kelurahan, tbl_pendataan, tbl_kecamatan. Dan memiliki relasi one to meny (satu ke banyak) seperti entitas pada himpunan entitas tbl_kelompok_koperasi, tbl_koperasi, tbl_kecamatan, tbl_kelurahan, tbl_pendataan untuk relasinya yaitu mengimputan data. Seperti di tunjukan pada Gambar 4.

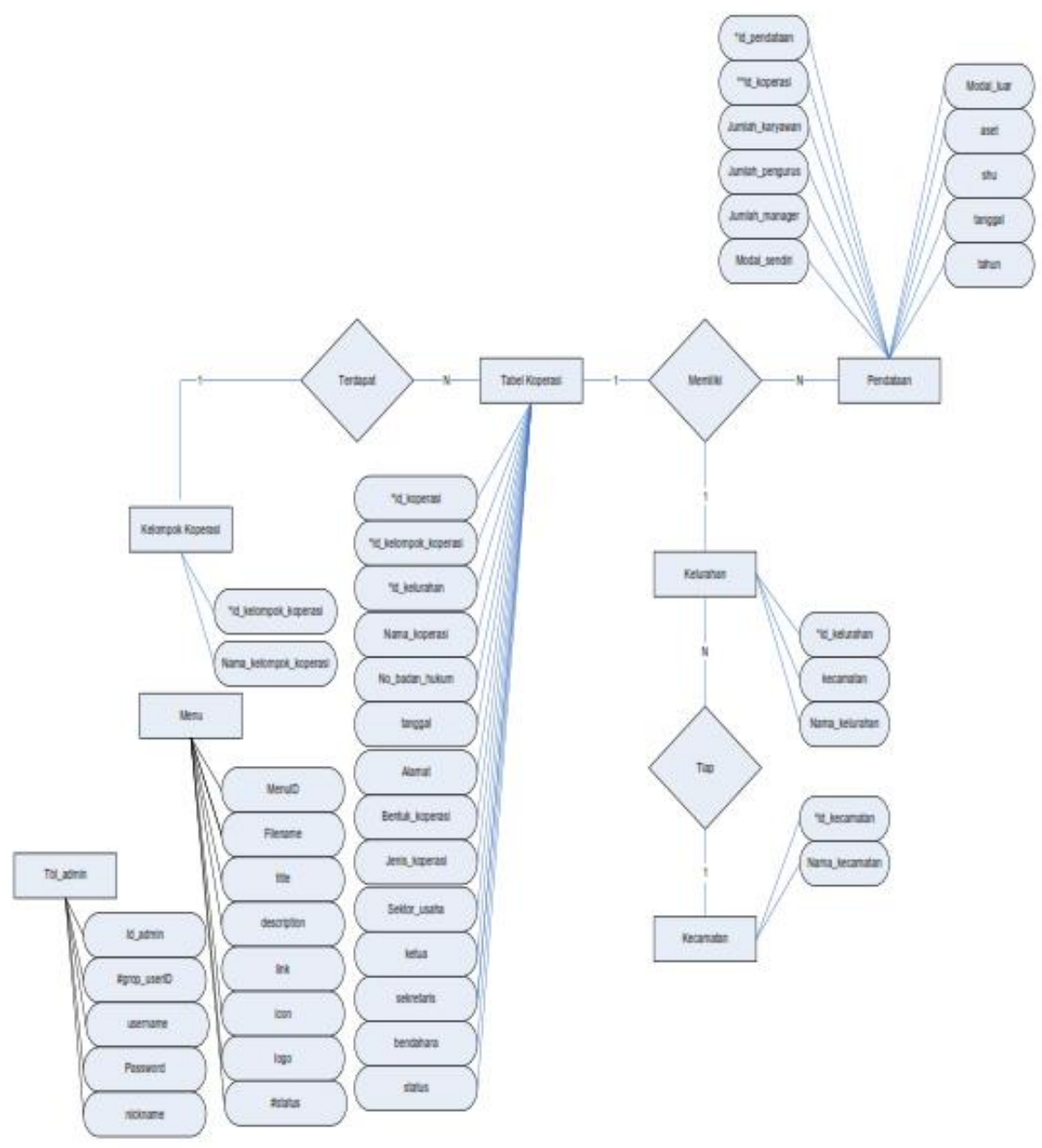

Gambar 4. ERD Sistem Pendataan Koperasi

\section{HASIL DAN PEMBAHASAN}

\subsection{Analisa Kebutuhan Sistem}

Sistem informasi pendataan koperasi pada Dinas Koperasi dan UKM Kota Ternate dalam pembuatan dan penerapannya membutuhkan ketersediaan jaringan internet. Pada pembuatannya sendiri dibutuhkan server lokal yang menciptakan seperti keadaan di mana tersedia server sebagai penyedia layanan dan klien yang meminta layanan. Bahasa pemrograman internet (html, php, cms) digunakan untuk mendesain tampilan dan melalukan manipulasi algoritma, sedangkan MySQL digunakan dalam manipulasi data basis data. 


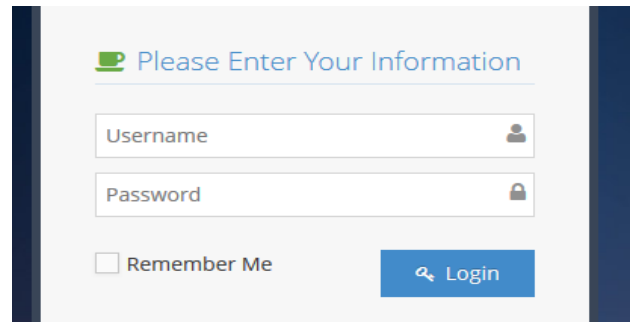

Gambar 8. Tampilan Login User Admin

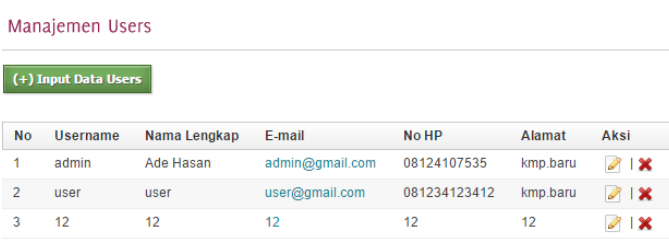

Gambar 9. Tampilan Penambahan User

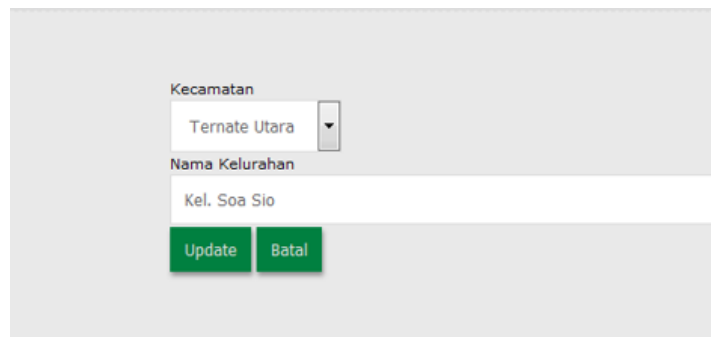

Gambar 10. Tampilan Input Data Kelurahan

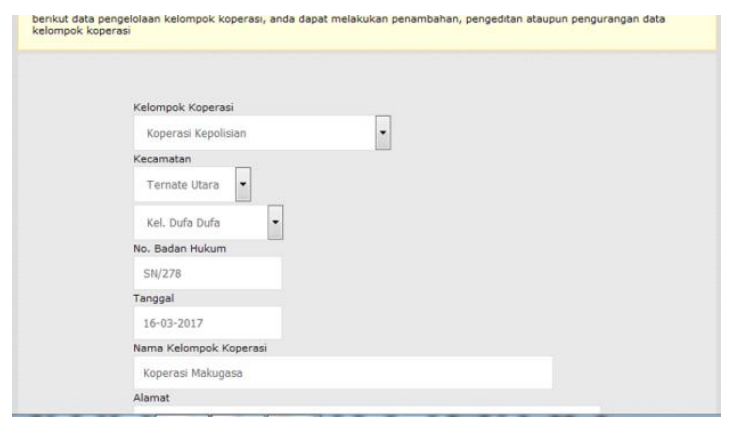

Gambar 11. Tampilan Input Data Koperasi

\subsection{Analisa Kemampuan Sistem}

Dari hasil ujicoba yang dilakukan terlihat kemampuan sistem informasi pendataan koperasi pada Dinas Koperasi dan UKM Kota Ternate untuk menginput tabel master kecamatan dan kelurahan dapat dilakukan. Penginputan tabel master harus dilakukan terlebih dahulu baru kemudian dilakukan penginputan data koperasi.

Segala macam modifikasi data hanya bida dilakukan oleh user admin melalui pengaksesan dengan memasukkan usernama dan password sebagai bentuk dari keamanan sistem. User biasa hanya bisa melihat dan menyortir data tanpa bisa melakukan manipulasi terhadap data (isi tabel).

\section{KESIMPULAN DAN SARAN}

\subsection{Kesimpulan}

Dari hasil penelitan yang telah dilaksanakan dapat disimpulkan hal-hal sebagai berikut:

1. Pembuatan sistem informasi pendataan koperasi berbasis web dapat dilakukan dengan menggunakan bahasa pemrograman HTML, PHP, CSS dengan memanfaatkan Dreamweaver sebagai Integrated Development Environment (IDE). Pembuatan basis data juga dapat dilakukan dengan memanfaatkan MySQL seabagai Database Management System (DBMS).

2. Pengolahan data koperasi dapat dilakukan dengan lebih cepat dalam hal penyimpanan dan dapat mencari data koperasi dengan lebih cepat dibandingkan dengan cara manual.

3. Lebih menghemat tempat karena hanya memanfaatkan media penyimpanan digital yang ukurannya sangat lebih kecil dibandingkan dengan ukuran lemari.

4. Data koperasi akhirnya dapat diakses dari mana saja dengan memanfaatkan koneksi internet

\subsection{Saran}

Setelah pembuatan sistem pendataan koperasi berbasis web, terdapat beberapa saran yang bisa diberikan, yaitu:

1. Dapat menambahkan data tentang kegiatan koperasi per bulan seperti data pendapatan per bulan, untuk dapat melihat keatifan setiap bulan.

2. Data anggota juga sebaiknya dapat diinput ke dalam sistem.

3. Agar point 1 dan 2 di atas maka sebaiknya diberikan hak akses untuk koperasi yang ada terhadap sisstem pendataan koperasi ini.

\section{DAFTAR PUSTAKA}

[1] Yakub. 2012. Pengantar Sistem Informasi. Penerbit Graha Ilmu: Yogyakarta, ISBN 978979-756-807-8.

[2] Ruslan, Takdir. 2014. Laporan Kerja Praktek (Sistem Informasi Koperasi). Penerbit Fakultas Teknik: Universitas Muhammadiyah maluku Utara.

[3] Kusdiawan 2010. Skripsi (Pendataan Perpustakaan). Penerbit Fakultas Teknik: Universitas Muhammadiyah maluku Utara.

[4] Fadli , Nur Quszaini. 2014. Skripsi (Membangun Aplikasi Pendataan Surat Masuk Pada Dinas Koperasi dan UKM Kota Semarang). Penerbit Fakultas Ilmu Komputer: Universitas Dian Nuswantoro. 
JIKO (Jurnal Informatika dan Komputer) Ternate

[5] Kadir, Abd. 2014. Pengantar Sistem Informasi. Penerbit Graha Ilmu: Jakarta, ISBN 978-979-756-807-8.

[6] Kristanto, Andri. 2012. Rekayasa Perangkat Lunak (Konsep Dasar). Penerbit Gava Media: Yogyakarta.

[7] Said, Abd. 2007. Skripsi (Peranan Dinas Koperasi dan UKM Dalam Pemberdayaan Pemerintah dan Masyarakat Kota Malang). Penerbit Fakultas Teknik: Universitas Islam Malang. 